This is the final peer-reviewed accepted manuscript of

SCARNATO, LUCILLA; MONTANARI, CHIARA; SERRAZANETTI, DIANA ISABELLA; ALOISI, IRIS; BALESTRA,

FEDERICA; DEL DUCA, STEFANO; LANCIOTTI, ROSALBA: New bread formulation with improved rheological properties and longer shelf-life by the combined use of transglutaminase and sourdough. LEBENSMITTEL-

WISSENSCHAFT + TECHNOLOGIE 81. 0023-6438

DOI: 10.1016/j.Iwt.2017.03.042

The final published version is available online at: http://dx.doi.org/10.1016/j.lwt.2017.03.042

Rights / License:

The terms and conditions for the reuse of this version of the manuscript are specified in the publishing policy. For all terms of use and more information see the publisher's website.

This item was downloaded from IRIS Università di Bologna (https://cris.unibo.it/)

When citing, please refer to the published version. 


\title{
New bread formulation with improved rheological properties and longer shelf-life by the combined use of transglutaminase and sourdough
}

\author{
Lucilla Scarnato $^{\mathrm{a}}$, Chiara Montanari ${ }^{\mathrm{b}}$, Diana Isabella Serrazanetti ${ }^{\mathrm{b}}$, Iris Aloisi ${ }^{\mathrm{a}}$, \\ Federica Balestra ${ }^{b}$, Stefano Del Duca ${ }^{\text {a, }}{ }^{*}$, Rosalba Lanciotti ${ }^{\text {b, c }}$ \\ a Department of Biological, Geological and Environmental Sciences, University of Bologna, Via Irnerio 42, 40126 Bologna, Italy \\ ${ }^{\mathrm{b}}$ Interdepartmental Center for Industrial Agro-food Research, University of Bologna, P.zza Goidanich 60, 47521 Cesena (FC), Italy \\ ${ }^{c}$ Department of Agricultural and Food Science, University of Bologna, Campus of Food Science, P.zza Goidanich 60, 47521 Cesena (FC), Italy
}

\section{A R T I C L E I N F O}

Keywords:

Transglutaminase

Sourdough bread

Shelf-life

Protein network

Volatile compounds

Chemical compounds:

4-methyl-2-pentanol (PubChem CID: 7910)

bicinchoninic acid (PubChem CID: 71068)

biotinyl cadaverine (PubChem CID: 83906)

\begin{abstract}
A B S T R A C T
The combined use of the protein reticulating enzyme transglutaminase (TGase) and a selected microbial consortium of Lactobacillus sanfranciscensis and Candida milleri for improving the rheological properties, aroma, and shelf life of a bakery product was evaluated. A microbial TGase, showing the highest activity over a wide temperature range on different protein substrates, was selected among different types. Results showed that this TGase was able to produce isodipeptide bonds, especially in the gluten fraction, leading to the formation of protein aggregates, which improved the structure of a sourdough bakery product. The microbial TGase in combination with sourdough exhibited a positive synergistic effect allowing the production of flavor enriched bread, with rheological properties similar to those of standard bread.
\end{abstract}

\section{Introduction}

Bread is a fundamental food in the Western world and it is

Abbreviations used: acTGase, Activa WM transglutaminase; AEC, 3-amino-9ethylcarbazole; ANOVA, analysis of variance; AtPng1p, Arabidopsis thaliana pep-tide $\mathrm{N}$-glycanase; CFU, colony forming unit; C, control; $\mathrm{Cd}$, control dough; $\mathrm{Cb}$, conventional bread; DY, dough yield; DMC, $N^{\prime}, N^{\prime}$-dimethyl casein; FN, fibronectin; SPME-GC-MS, gas chromatography-mass spectrometry coupled with solid phase micro-extraction; HRP, horseradish peroxidase; LAB, lactic acid bacteria; PC, principal component; PCA, principal component analysis; Sd, selected sourdough; Sb, sourdough bread; TGase, transglutaminase; TPA, texture profile analysis; MCFA, medium-chain fatty acid; RT, room temperature; SDS-PAGE, sodium dodecyl sulphate poly acrylamide gel electrophoresis; VCs, volatile compounds.

* Corresponding author. Department of Biological, Geological and Environmental Sciences, University of Bologna, Via Irnerio 42, 40126 Bologna, Italy. Tel.: +39 051 2091283; fax: +39051242576.

E-mail addresses: lucilla.scarnato@unibo.it (L. Scarnato), chiara.montanari8@ unibo.it (C. Montanari), diana.serrazanetti3@unibo.it (D.I. Serrazanetti), iris. aloisi2@unibo.it (I. Aloisi), federica.balestra@unibo.it (F. Balestra), stefano. delduca@unibo.it (S. Del Duca), rosalba.lanciotti@unibo.it (R. Lanciotti). generally viewed as a perishable commodity, due to its fast decrease of freshness features and its rapid staling (Minervini, De Angelis, Di Cagno, \& Gobbetti, 2014). Lactic acid bacteria (LAB) and yeasts in the form of sourdough have been reported to have positive effects on wheat bread quality and staling (Clarke, Schober, \& Arendt, 2002; Corsetti et al., 2000; Crowley, Schober, Clarke, \& Arendt, 2002) as they are responsible for the capacity of dough to leaven, while acidifying it (De Vuyst \& Neysen, 2005). Traditional sourdough obtained with selected microorganisms is able to in crease bread shelf life by delaying staling (Chavan \& Chavan, 2011) and improve bread properties through enhancing its nutritional value, taste, and aroma profile (Arendt, Ryan, \& Dal Bello, 2007; Hansen \& Schieberle, 2005; Poutanen, Flander, \& Katina, 2009). However, the use of LAB may affect the rheology of leavened bakery products through a strain dependent proteolytic activity (Gobbetti, Smacchi, \& Corsetti, 1996). These rheological properties, besides gas retention, depend on gluten proteins, composed of extensible, viscous gliadins and rigid, elastic glutenins. Chemical agents or 
cross linking enzymes, such as glucose oxidase, peroxidase, or transglutaminase (TGase), have been reported to improve dough handling properties and to increase fermentation stability, and loaf volume (Caballero, Gómez, \& Rosell, 2007; Steffolani, Ribotta, Perez, \& Leon, 2010). In particular, TGase (EC 2.3.2.13) is an important enzyme for the food industry (Basman, Koksel, \& Ng, 2002) as it catalyses the formation of protein cross links resulting in extensive nets (Nonaka et al., 1989). The formation of protein polymers, as a result of TGase activity, can modify the rheological properties of gluten (Koksel, Sivri, Ng, \& Steffe, 2001) and allow the transformation of a very weak gluten into a very strong one (Larre et al., 2000). In previous studies, the positive effects of TGase application on wheat based baked products have been described (Renzetti, Behr, Vogel, \& Arendt, 2008), (Gerrard et al., 2000). The effects of TGase on empirical rheological properties of dough (Basman et al., 2002; Marco, Perez, Ribotta, \& Rosselli, 2007) and on the formulation of sourdough (Arendt et al., 2007; Clarke et al., 2002) in order to obtain good quality bread have been described. To date, however, the combined use of the two biological agents,

i.e., TGase and sourdough, has never been reported.

In the present work, we tested the possibility of improving bread quality through the combined use of sourdough and a protein reticulating enzyme. TGase was selected in order to improve rheology (Gerrard et al., 1998), while sourdough based on Lactobacillus sanfranciscensis and Candida milleri was chosen for its ability to improve the aroma profiles and extend the shelf life of the final product (Scarnato et al., 2016; Vernocchi et al., 2008). L. sanfranciscensis is a key organism for sourdough acidification and produces aroma precursors (Gobbetti et al., 1996; Ganzle, Vermeulen, \& Vogel, 2007), while C. milleri is able to grow in as sociation with hetero fermentative LAB, enhancing the accumulation of specific aroma compounds, including alcohols, lactones, and medium chain fatty acids (MCFAs) (Gobbetti, 1998; Ganzle, Ehmann, \& Hammes, 1998). Results show that the combination of a protein reticulating enzyme and sourdough on wheat bread produced a positive synergistic effect.

\section{Materials and methods}

\subsection{Materials}

Straight grade wheat flour was provided by Barilla S.p.A.(Parma, Italy). The TGases tested in this study came from different sources: (i) Activa ${ }^{\circledR}$ WM (acTGase), from Streptoverticillum mobar aense, was purchased from Ajinomoto (specific activity: $>0.1 \mathrm{U} / \mathrm{mg}$ powder preparation whose composition is 1\% enzyme and $99 \%$ maltodextrin), Mesnil Saint Nicaise, France, (ii) a recombinant microbial TGase (zTGase) was purchased from Zedira (specific ac tivity: > $25 \mathrm{U} / \mathrm{mg}$, Darmstadt, Germany), (iii) a mammalian TGase, from guinea pig liver, was purchased from Sigma Aldrich (specific activity: $>2.4 \mathrm{U} / \mathrm{mg}$, Milan, Italy), and (iv) a recombinant TGase of plant origin, the Arabidopsis thaliana peptide $N$ glycanase (AtPng1p), was purified as previously described (Della Mea, Caparros Ruiz, \& Rigau, 2004) (specific activity: > $0.5 \mathrm{U} / \mathrm{mg}$ ).

All reagents and solvents (unless otherwise indicated) were of the highest purity and were obtained from Sigma Aldrich (Milan, Italy).

\subsection{Sourdough preparation}

Sourdough was prepared by a two step fermentation process using L. sanfranciscensis strain LSCE1 and C. milleri strain PFL44, both belonging to the Department of Agricultural and Food Science, University of Bologna (Italy). The dough was prepared by mixing wheat flour and water to reach a dough yield (DY) of 220. Exposure to osmotic stress was performed by adding sucrose (40\% of the final dough volume) to the water. Fermentation was performed in a fermentor (BioFlo/CelliGen ${ }^{\circledR}$ 115, New Brunswick, Eppendorf) as previously described (Scarnato et al., 2016). The sourdough obtained was used for the preparation of bread in association or not with TGase.

\subsection{Enzymatic treatment with TGase}

In order to induce protein cross links, different amounts of TGase $(0.5,1,2$, and $5 \mathrm{U} / \mathrm{g}$ flour) were added to the wheat dough (Cd) obtained using Saccharomyces cerevisiae as a conventional leavening agent and the sourdough (Sd) made with the selected microbial consortium described above. The enzyme was mixed to the flour for 15,60 or $90 \mathrm{~min}$ at different temperatures, from 4 to $37^{\circ} \mathrm{C}$.

Cross linking was evaluated by protein extraction and separation using $15 \%$ sodium dodecyl sulphate polyacrylamide gel electrophoresis (SDS PAGE). Total proteins were extracted under reducing conditions using the buffer described by (Marco et al., 2007). Albumins/globulins (F1), prolamins (F2), and glutelins (F3) were extracted following a sequential extraction method using different solvents (Marco et al., 2007). Globulins 7S and 11S were prepared and purified as previously described (Thanh, Okubo, \& Shibasaki, 1975). The protein content of the extracts was deter mined by the bicinchoninic acid method (Smith et al., 1985).

\subsection{Measurement of TGase activity}

TGase specific activity was measured by the conjugation of biotinylated cadaverine to protein substrates as previously described (Lilley, Skill, Griffin, \& Bonner, 1998) with slight modifications. Protein substrates, such as standard proteins and wheat protein extracts, were covalently attached to the surface of microplate wells. The level of biotinylated cadaverine incorporation was determined according to an established protocol (Lilley et al., 1998) with $10 \mathrm{mM}$ cystamine replacing EDTA in negative controls. The specific activity was expressed as a 0.1 change in $A_{450}$ per h per mg of TGase used (U/mg prot.).

\subsection{Dot blot of enzyme reaction products}

Fractions F1, F2, and F3 were treated with TGase and the reaction products were blotted onto nitrocellulose. The membrane was incubated with $A b 3$, a monoclonal antibody raised against soluble TGase (Neomarker, Fremont, CA, U.S.A.) and with 81D4, a monoclonal anti $\mathrm{N} \varepsilon$ ( $\gamma$ glutamyl) lysine antibody (Covalab, Lyon, France), which is a product of the TGase cross linking reaction. Dots were revealed using horseradish peroxidase (HRP) conjugated rabbit antimouse IgG and 3 amino 9 ethylcarbazole (AEC).

\subsection{Bread preparation}

Bread was prepared with a bread maker (Deluxe Princess, 152000) using an industrial recipe (wheat flour, water, sugar, salt, baker's yeast, and extra virgin olive oil) to obtain a final volume of about $500 \mathrm{~g}$ with DY 150 . When Sd was used, it was added at a concentration of about $30 \%$ of the final weight of dough; the amount of flour and water was reduced accordingly in order to maintain the same DY. TGase was added at different concentrations $(0.5,1$, and $2 \mathrm{U} / \mathrm{g}$ flour). Doughs were kneaded for $14 \mathrm{~min}$ and fermented for $20 \mathrm{~min}$. Then, a second kneading of 8 min was performed, followed by $1 \mathrm{~h}$ of fermentation. Dough samples Cd, and Sd with and without TGase were then baked at $180{ }^{\circ} \mathrm{C}$ for $30 \mathrm{~min}$ in order to obtain conventional bread $(\mathrm{Cb})$ and sourdough bread $(\mathrm{Sb})$. 


\subsection{Bread empirical rheological properties}

Bread mechanical characteristics were evaluated with a Texture Analyzer mod. TA.HDi 500 (Stable Micro System, Godalming, Surrey, UK) equipped with a $\mathrm{P} / 20 \mathrm{~mm}$ aluminium cylinder probe and a $25 \mathrm{~kg}$ load cell. For each sample, three slices of $15 \mathrm{~mm}$ were cut from the central portion of two different bread loaves. Texture profile analysis (TPA) and stress relaxation tests were performed. The TPA test in a double compression cycle was performed as described earlier (Gàmbaro et al., 2002). Four textural parameters, expressed as hardness, resilience, cohesiveness, and chewiness of the crumb were used as indicators of structural characteristics. The stress relaxation test was performed as described by (Stollman \& Lundgren, 1987); texture parameters, such as hardness and springiness, were determined.

\subsection{Bread image analysis}

The inner portion of bread slices was used for crumb grain features measurements. A digital camera mod. D7000 (Nikon, Shinjuku, Japan) was used to acquire digitalized images of samples placed inside a black box under controlled lighting conditions. The slice images were spatially calibrated using Image Pro Plus v. 6.2 (Media Cybernetics, USA). Grey levels of scanned slices were evaluated by the model in terms of percentage holes and crumb area over the total. The percentage crumb porosity on the total alveolation of the slice portion was determined. Moreover, crumb morphological features were evaluated including the cell area distribution. Holes were identified, counted and classified into four predefined area classes on the basis of their size $(\mathrm{cm} 2)$ : $0.00025<$ class $1<0.025 ; 0.025<$ class $2<0.25 ; 0.25<$ class $3<0.5 ; 0.5<$ class $4<1$.

Finally, the aspect ratio was calculated by dividing the width by the height of the bread slices (Collar \& Angioloni, 2014).

\subsection{Bread shelf life evaluation}

After a 2 h cooling period, bread samples ( $\mathrm{Cb}$ and $\mathrm{Sb}$ ) were introduced in polyethylene plastic bags in ordinary atmosphere, sealed and stored at room temperature (RT) $\left(24 \pm 2{ }^{\circ} \mathrm{C}\right)$ for 15 days without preservatives. Samples were monitored daily to check for the presence of spoilage microflora (molds and Bacillus spp.); microbial growth was tested by plate counting after 7 and 15 days. Analyses were performed on Malt Extract Agar (Oxoid, Basingstoke, UK) for molds and on Plate Count Agar (Oxoid, Basingstoke, UK) for Bacillus spp.

\subsection{SPME Gas Chromatography Mass Spectrometry analysis}

Volatile compounds (VCs) were monitored by using Gas Chromatography Mass Spectrometry coupled with solid phase micro extraction (SPME GC MS). Doughs (Cd and Sd) and baked samples ( $\mathrm{Cb}$ and $\mathrm{Sb}$ ) were placed in sterilized vials and $10 \mathrm{ml}$ of 4 methyl 2 pentanol (final concentration $33 \mathrm{mg} / \mathrm{kg}$ ) were added as the internal standard. Samples were pre equilibrated for $10 \mathrm{~min}$ at $47{ }^{\circ} \mathrm{C}$ and then a fused silica fibre, covered with divinylbenzene/ carboxen/polydimethylsiloxane (DVB/CAR/PDMS StableFlex, Supelco, Steiheim, Germany), was introduced in the head space for $40 \mathrm{~min}$. Molecules were detected using the method described by (Montanari et al., 2014). Identification was based on the comparison of mass spectra with those of NIST and Wiley databases. VCs were expressed as a percentage of the total peak area. Identification of MCFAs was also confirmed by comparing their retention times with those of pure compound mixtures (e.g., BAME Mix, Sigma
Aldrich, Italy). Only identified compounds reaching concentrations above $0.2 \%$ of the total peak area were used for subsequent Principal Component Analysis (PCA) according to (Patrignani et al., 2016). However, a preliminary one way analysis of variance (ANOVA; significance $\mathrm{P} \leq 0.05$ ) was performed to confirm that the excluded peaks were not significant for sample characterization.

\subsection{Statistical analysis}

The data are the means of three replicates and are expressed as mean \pm standard deviation. The data were examined using one and two way ANOVA with a significant difference of at least 95\% according to the Bonferroni post test (GraphPad Prism software), ${ }^{* *}$ $\mathrm{p} \leq 0.01$.

Textural data were compared by the Kruskal Wallis test in case of significance with the Levene test $(p<0.05)$ (Statistica 8.0, Stat Soft Inc., Tulsa, OK, U.S.A).

\section{Results}

\subsection{Comparison of TGase activities on different protein substrates}

Initially, the four different TGases (acTGase; zTGase; gplTGase and AtPng1p) were tested on well known protein substrates of TGase, such as dimethylcasein (DMC), fibronectin (FN), and some protein fractions present in flours, i.e., $7 \mathrm{~S}$ and $11 \mathrm{~S}$ globulins (from soybean), prolamins, gluten, and glutenins from wheat. All the TGases showed activity on the tested substrates. The two TGases of microbial origin (acTGase and zTGase) showed the highest specific activity that reached $4000 \mathrm{U} / \mathrm{mg}$ prot (Fig. 1A). gplTGase also showed high activity on these substrates with activities $>1000 \mathrm{U} /$ mg prot. Moreover, the two microbial TGases showed the highest activity on gluten and its components, gliadins and glutenins. When 11S globulins, glutenins, and gliadins were incubated with the various enzymes at different temperatures for $90 \mathrm{~min}$ in order to evaluate their cross linking effect, varying degrees of substrate aggregation were visible by SDS PAGE in regions corresponding to high molecular weight (HMW), compared to the same protein not treated with the enzyme (Fig. 1B). At $30^{\circ} \mathrm{C}$, AtPng1p, gplTGase, and acTGase were efficient in the cross linkage of $11 \mathrm{~S}$ globulin. Both microbial TGases were very effective in reticulating all the tested substrates in a wide range of temperatures $\left(4-37^{\circ} \mathrm{C}\right)$. As acTGase showed the highest activity on the different protein substrates, with major aggregating effects at $30{ }^{\circ} \mathrm{C}$, it was chosen for subsequent experiments.

\section{2. acTGase mediated cross linking in dough}

As a first attempt to investigate the cross linking activity of acTGase on wheat dough, different enzyme dosages $(0.5,1,2$, and 5 $\mathrm{U} / \mathrm{g}$ flour) were added. The formation of HMW proteins was dependent on enzyme dosage, mixture time, and water amount. In order to acquire information about the proteins involved in the cross links, different protein fractions (F1, F2, and F3) were extracted from dough. Protein separation by SDS PAGE showed that acTGase, increased the formation of HMW products mostly in F2 and F3 (Fig. 2A, brackets). This was confirmed by the enzyme activity assay, showing that F2 and F3 were the best acTGase substrates as measured by incorporation of cadaverine (Fig. 2B). Moreover, the immune recognition of the signal corresponding to acTGase increased in supernatants while the appearance of cross links increased in the pellets, as shown in dot blot experiments. F2 showed cross linked products at the lowest acTGase concentration (0.5 U/g flour) (Fig. 2C). 
A
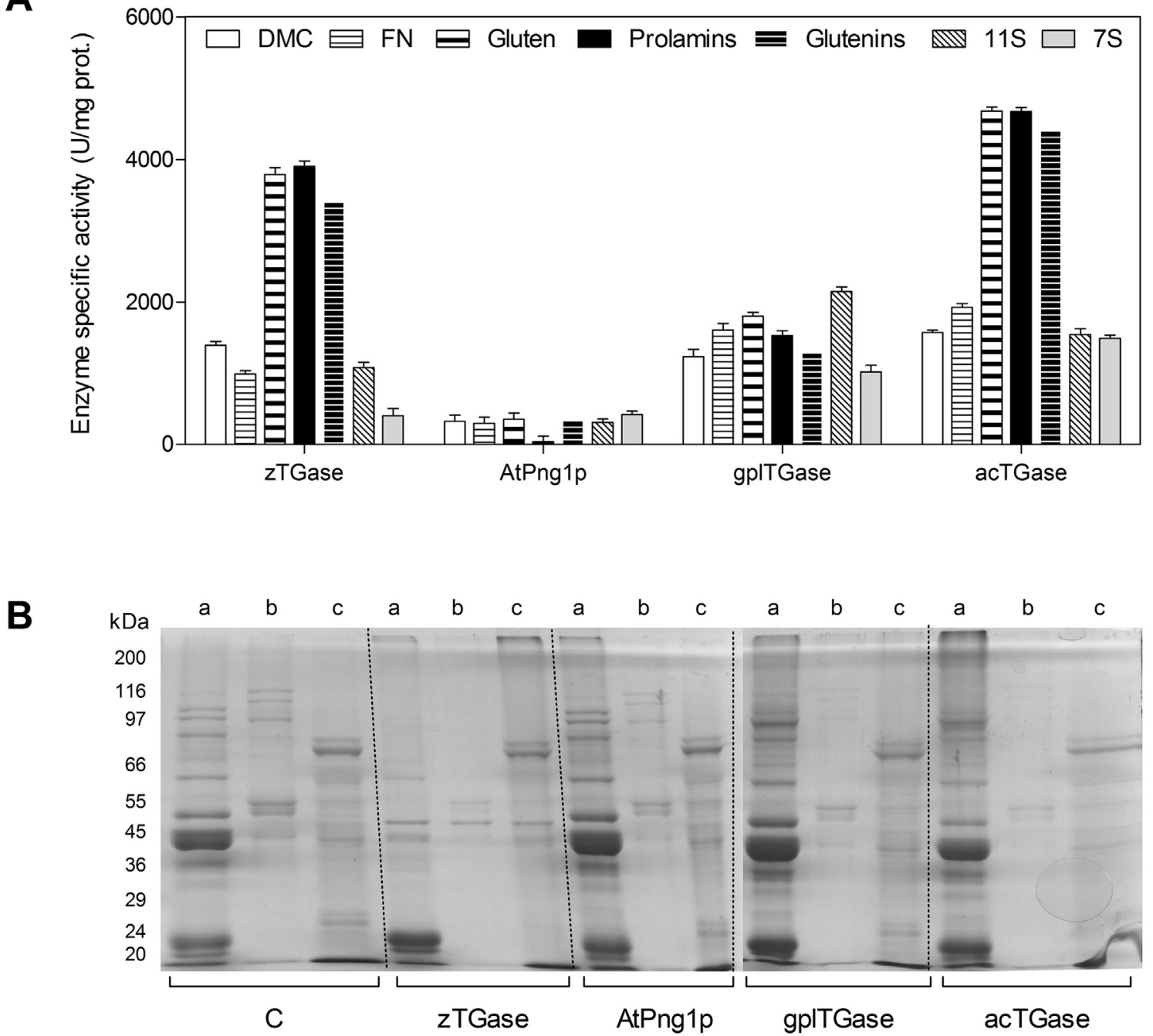

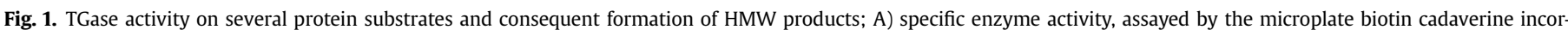

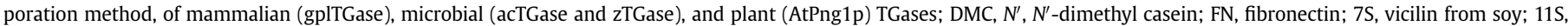

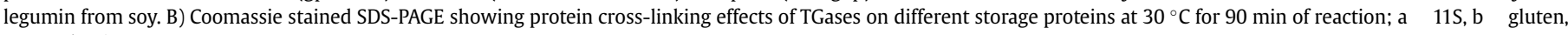
c prolamins.

\subsection{Combined effects of acTGase and sourdough on proteins}

The formation of HMW products, both in Cd and Sd, was analysed by separation of the total protein extract before and after acTGase treatment. As shown in Fig. 3A (bracket), HMW products were enhanced by the presence of the sourdough. TGase activity on fractions F1, F2, and F3 extracted from Cd and Sd confirmed that the presence of sourdough significantly increased enzyme activity in a synergistic way as compared with Sd alone, which was not active (Fig. 3 B).

\subsection{Physicochemical and rheological features of baked samples}

As reported in Table $1, \mathrm{Cb}$ was the softest sample, as it exhibited the lowest hardness value (248 g) as compared with the other samples. With increasing amounts of acTGase, the baked samples reached hardness values of $642 \mathrm{~g}, 1060 \mathrm{~g}$, and $1177 \mathrm{~g}$ with $0.5 \mathrm{U}, 1 \mathrm{U}$ and $2 \mathrm{U}$ of enzyme, respectively. Hardness was significantly reduced to values around $500 \mathrm{~g}$ when the same units of enzyme were added to $\mathrm{Sb}$. A similar trend in the chewiness parameter was observed as the forces values rose after the addition of acTGase, while in Sb this value remained almost constant even after enzyme addition. Samples made with $\mathrm{Sb}$ and acTGase had lower hardness and chewiness values compared to $\mathrm{Cb}$ plus enzyme in a dose dependent manner. $\mathrm{Cb}$ showed the highest value of cohesiveness and resilience, freshness index, and softness. A reduction of these values was obtained by increasing the enzyme units, while adding the sourdough had no significant effects because it counteracted those induced by the enzyme. Results obtained in the stress relaxation test showed a similar trend to those obtained in the TPA, confirming the synergic benefit of sourdough in combination with acTGase (Table 1 ).

\subsection{Crumb morphological features of baked samples}

Bread crumb gas cell size of baked samples were investigated as they have a significant effect on bread texture and on mouth feel perception. As reported in Table 2, similar porosity values, expressed as percentage of hole areas, were observed in all bread slices. All samples were characterized by a fine crumb, i.e., gas cells belonging to classes 1 and 2 in most of the area. The effect of sourdough and acTGase (all concentrations) combined caused an 
A

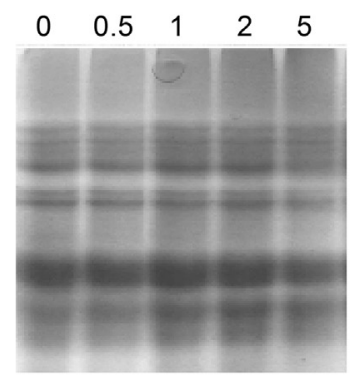

F1

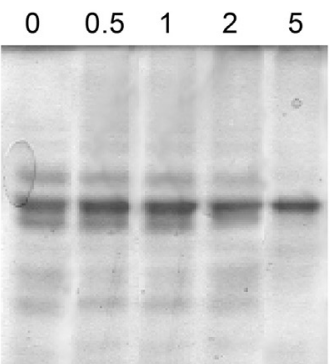

F2

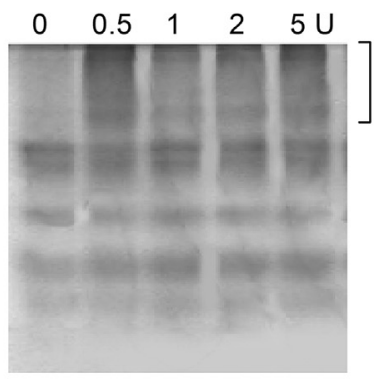

F3
B

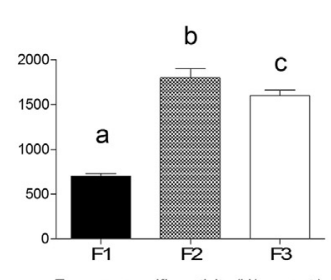

Enzyme specific activity (U/mg prot.)
C
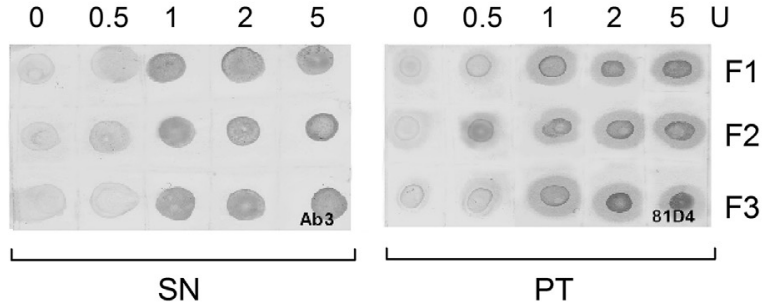

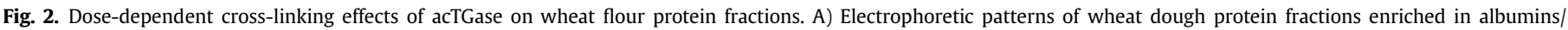

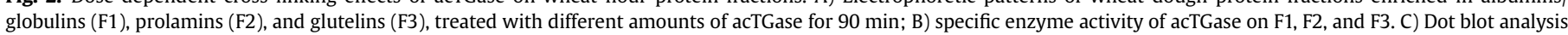
of F1, F2, and F3 treated with different amounts of acTGase and probed with the Ab3 antibody against TGase (supernatant, SN) and 81D4 against cross-links (pellet, PT).

increase in class 2 gas cells but not class 1 .

The aspect ratio, an index of product volume, showed that acTGase caused a volume reduction of the slice in a dose dependent manner. The presence of sourdough, in combination with acTGase, increased the volume of the slice, bringing aspect ratio values close to the control sample (Fig. 4). In particular, $\mathrm{Cb}$ had the lowest aspect ratio value $(0.83 \pm 0.04)$, which increased in a dose dependent manner in samples treated with increasing acT Gase units, reaching values of $1.26 \pm 0.06$. Sb had an aspect ratio of $1.00 \pm 0.03$, while the addition of $1 \mathrm{U}$ of acTGase slightly decreased this value to $0.96 \pm 0.01$ (Table 2 ).

\subsection{Combined effect of acTGase and sourdough on volatile compounds}

The VC profiles of dough and breads, both $\mathrm{Cb}$ and $\mathrm{Sb}$ treated or not with acTGase, were determined by GC MS SPME. This approach has proven its potential in providing a VC fingerprint of food and beverages in relation to their microbiota, composition, and/or production processes (Montanari et al., 2016; Patrignani et al., 2016; Scarnato et al., 2016). Sixty molecules belonging to different chemical classes were identified and specific VC finger prints were obtained in relation to the treatment and before and after baking. In particular, $\mathrm{Cb}$ was mainly characterized by ethanol, phenylethyl alcohol, and furanones. The addition of TGase and sourdough caused a significant modification of the profile. Since profiles were very complex, data was subjected to PCA. All the samples were mapped in the space spanned by the first two principal components, with PC1 and PC2 explaining 35.48 and $26.00 \%$ of the variance, respectively. The score plot showed that samples were clustered mainly according to the baking process and the presence of sourdough (Fig. 5A). Samples were separated into four clusters; cluster 1 grouped $\mathrm{Cb}$ samples with and without acTGase, while cluster 2 comprised $\mathrm{Sb}$ samples, independent of the enzyme addition. Clusters 3 and 4 included Sd and Cd, respectively. The presence of sourdough separated samples Sd and Sb along PC1 regardless of the presence of the enzyme. The baking process differentiated the samples ( $\mathrm{Sb}$ and $\mathrm{Cb}$ ) along $\mathrm{PC} 2$. As shown by the loading plots (Fig. 5B), the presence of sourdough strongly affected VC profiles independent of the baking process and enzyme addition. In fact, clusters 2 and 3 were characterized by the highest contents of molecules deriving from the activities of sourdough microbiota, including ketones, MCFAs, and alcohols. VCs such as furanone and phenyl ethyl alcohol characterized the baked samples.

\subsection{Shelf life of baked products}

In order to evaluate the impact of sourdough fermentation on shelf life, the baked samples were monitored during 15 days of storage at RT. A relevant extension (up to 15 days) of the shelf life, in terms of microbial growth prevention (namely of molds and Bacillus spp), of bread obtained with sourdough and acTGase addition was observed. After 3 days of storage, the samples did not appear visibly different. After 7 days, $\mathrm{Cb}$ was characterized by the presence of molds on the surface. The microbiological analyses, performed at this sampling point, revealed levels of molds and Bacillus spp. higher than $5 \log \mathrm{CFU} / \mathrm{g}$, that reached about $8 \log \mathrm{CFU} /$ $\mathrm{g}$ after 15 days of storage. Differently in Sb plus acTGase these species remained under the detection limit after 7 days, while $3 \log$ $\mathrm{CFU} / \mathrm{g}$ were detected after 15 days of storage (Fig. 6A and B).

\section{Discussion}

In this work, both the acTGase enzyme and the microbial consortium consisting of $L$. sanfranciscensis and $C$. milleri alone showed advantages and disadvantages, the latter compensated by the supplementation of the two agents together. The final product showed enrichment in flavor and improved rheological properties. The interaction of microbially produced metabolites or flavor compounds with bread microstructure is generally underestimated and, therefore, not systematically investigated. However, (Aponte 


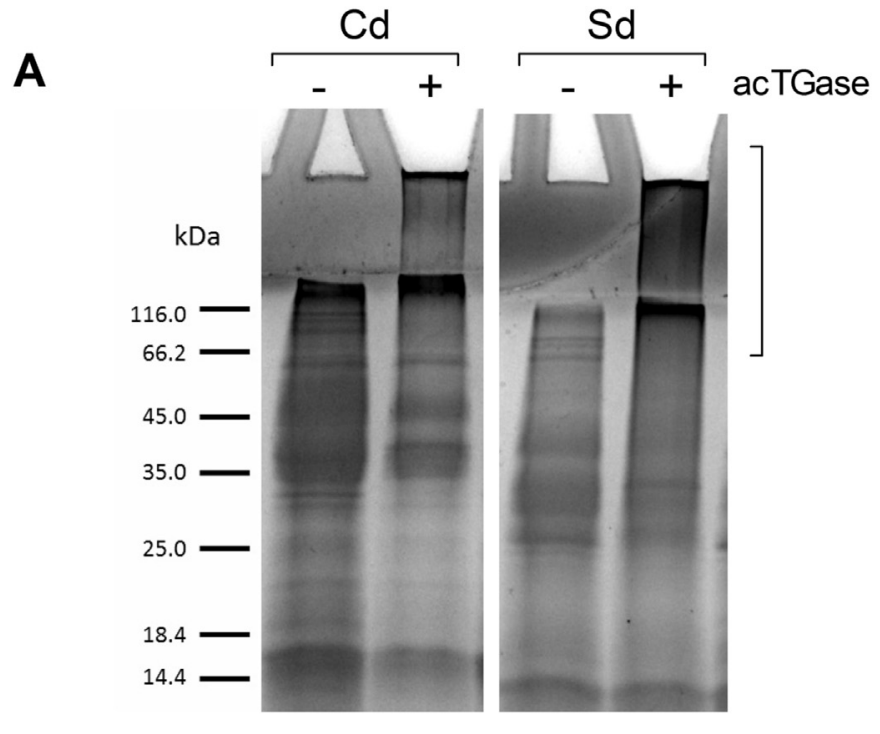

B

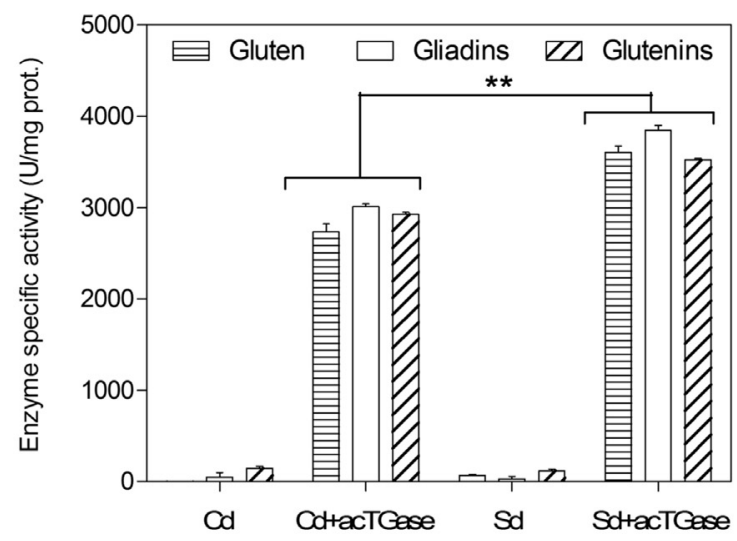

Fig. 3. Combined effects of acTGase and sourdough on wheat dough proteins. A) SDSPAGE highlighting HMW products (brackets) in total protein extracts from doughs treated with $0.5 \mathrm{U}$ of acTGase and sourdough; $\mathrm{Cd}$ conventional dough, $\mathrm{Cd}+$ acTGase conventional dough plus acTGase, Sd selected sourdough, $\mathrm{Sd}+$ acTGase selected sourdough plus acTGase; B) biotin cadaverine incorporation assay on wheat protein fractions (F1, F2 and F3) in the presence of acTGase and sourdough; $\mathrm{Cd}$ conventional dough, $\mathrm{Cd}+$ acTGase conventional dough plus acTGase, Sd selected sourdough, Sd + acTGase selected sourdough plus acTGase.

et al., 2014), studying the effect of fermentation time on the microstructure and volatile compounds of chestnut flour based sourdough, showed a significant relationship between the protein network surrounding starch globules and the VC composition of sourdough. Consequently, the specific VC fingerprints obtained here could also be the result of changes induced in the protein network by TGase and/or enzymatic activities of sourdough microflora.

The addition of acTGase led to detrimental effects on $\mathrm{Cb}$. The high hardness and chewiness values of $\mathrm{Cb}$ treated with acTGase was, however, counteracted by using sourdough obtained with the selected microbial consortium. These findings are in agreement with the hydrolysis of protein networks that occurs during sour dough fermentation, probably due to a $\mathrm{pH}$ mediated activation of cereal proteolytic enzymes (Loponen, Mikola, Katina, Sontag Strohm, \& Salovaara, 2004). It is known that LAB may affect product rheology through a strain dependent proteolytic activity (Gobbetti et al., 1996). On the other hand, degradation of wheat gluten would reduce the viscoelastic properties, responsible for the leavening capacity of bread and other baked products.

The main benefits deriving from the use of the microbial consortium were enriched in flavors, leavening and increased in shelf life. Moreover, it is well known that sourdough contributes to the quality of baked goods as it is rich in nutrients and other compounds with beneficial health effects (De Vuyst et al., 2014). Under our experimental conditions, sourdough increased the accumulation of some molecules, such as ketones, MCFAs, and alcohols. These findings are in agreement with evidences underlining that 1 propanol, 3 methyl 2 butanone, 3 hydroxy 2 butanone, and 2 and 3 methyl butanoic acid are the main VCs produced by selected LAB isolated from sourdough (Damiani et al., 1996). Moreover, the interaction between yeast and LAB in sourdough results in a significant enhancement of bread aroma profiles (Ganzle et al., 2007; Hansen \& Schieberle, 2005; Kirchhoff \& Schieberle, 2001). The proteolytic system of LAB releases low molecular weight peptides and amino acids, which promote the development of metabolic activity in the microorganisms, helping to obtain an improved taste and flavor due to their further production of aroma compounds (Di Cagno et al., 2005; Rizzello et al., 2007). The aroma profile of both dough and baked bread also results from osmotic stress. In fact the exposure of microbial cells to stressful conditions during the fermentation process induces a broad transcriptional response (Serrazanetti, Guerzoni, Corsetti, \& Vogel, 2009), reported to affect the organoleptic properties via several metabolic activities (Guerzoni, Vernocchi, Ndagijimana, Gianotti, \& Lanciotti, 2007). In particular, it has been reported that $L$. sanfranciscensis in sourdough responds to environmental stresses, with an overproduction of specific compounds such as 3 methyl butanoic acid and $2(5 \mathrm{H})$ furanones (Erasmus, Van Der Merwe, \& Van Vuuren, 2003; Guerzoni et al., 2007).

Concerning the effect of TGase on bread shelf life, Gottardi, Khoon Hong, Ndagijimana, and Betti (2014) reported that some

Table 1

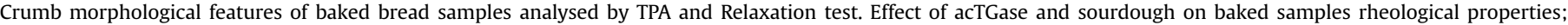

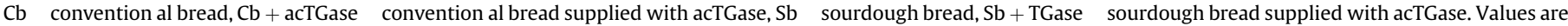

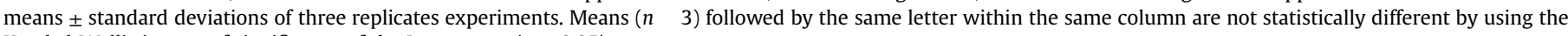
Kruskal-Wallis in case of significance of the Levene test $(p<0.05)$.

\begin{tabular}{|c|c|c|c|c|c|c|}
\hline \multirow[t]{2}{*}{ Bread samples } & \multicolumn{4}{|l|}{ TPA test } & \multicolumn{2}{|c|}{ Relaxation test } \\
\hline & Hardness (g) & Cohesiveness & Resilience & Chewiness (g) & Hardness (g) & Springiness (\%) \\
\hline $\mathrm{Cb}$ & $248 \pm 27 b$ & $0.80 \pm 0.02 \mathrm{a}$ & $0.47 \pm 0.01 \mathrm{a}$ & $197 \pm 18 b$ & $193 \pm 27 b$ & $55 \pm 0.58 \mathrm{a}$ \\
\hline $\mathrm{Cb}+\operatorname{acTGase}(0.5 \mathrm{U})$ & $642 \pm 39 a b$ & $0.69 \pm 0.02 a b$ & $0.38 \pm 0.03 a b$ & $439 \pm 18 a b$ & $367 \pm 28 a b$ & $48 \pm 3.08 \mathrm{a}$ \\
\hline $\mathrm{Cb}+$ acTGase $(1 \mathrm{U})$ & $1060 \pm 95 a$ & $0.67 \pm 0.01 \mathrm{ab}$ & $0.36 \pm 0.01 \mathrm{ab}$ & $709 \pm 74 a$ & $655 \pm 42 \mathrm{ab}$ & $49 \pm 1.21 \mathrm{a}$ \\
\hline $\mathrm{Cb}+$ acTGase $(2 \mathrm{U})$ & $1177 \pm 166 a$ & $0.62 \pm 0.05 a b$ & $0.28 \pm 0.04 b$ & $724 \pm 61 \mathrm{a}$ & $715 \pm 52 \mathrm{a}$ & $45 \pm 5.33 \mathrm{a}$ \\
\hline $\mathrm{Sb}$ & $456 \pm 5 a b$ & $0.67 \pm 0.01 \mathrm{ab}$ & $0.36 \pm 0.02 a b$ & $307 \pm 9 a b$ & $334 \pm 23 a b$ & $43 \pm 1.69 a$ \\
\hline $\mathrm{Sb}+$ acTGase $(0.5 \mathrm{U})$ & $548 \pm 96 a b$ & $0.60 \pm 0.04 b$ & $0.31 \pm 0.05 a b$ & $331 \pm 70 a b$ & $333 \pm 44 a b$ & $45 \pm 2.61 \mathrm{a}$ \\
\hline $\mathrm{Sb}+\operatorname{acTGase}(1 \mathrm{U})$ & $368 \pm 51 \mathrm{ab}$ & $0.71 \pm 0.02 \mathrm{ab}$ & $0.46 \pm 0.02 a$ & $260 \pm 32 a b$ & $213 \pm 32 a b$ & $45 \pm 2.56 \mathrm{a}$ \\
\hline $\mathrm{Sb}+$ acTGase (2 $\mathrm{U})$ & $494 \pm 43 a b$ & $0.67 \pm 0.03 a b$ & $0.40 \pm 0.02 a b$ & $330 \pm 14 a b$ & $210 \pm 21 \mathrm{ab}$ & $45 \pm 1.44 \mathrm{a}$ \\
\hline
\end{tabular}


Table 2

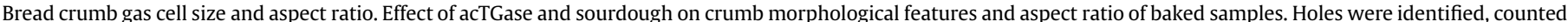

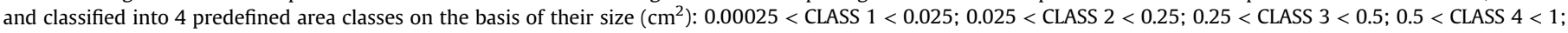

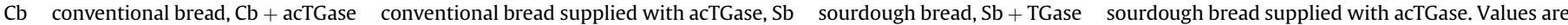
means \pm standard deviations of three replicates experiments.

\begin{tabular}{|c|c|c|c|c|c|c|}
\hline Bread samples & Area holes (\%) & Area crumb (\%) & Classes & Holes (\%) & Area (\%) & Aspect ratio \\
\hline \multirow[t]{4}{*}{$\mathrm{Cb}$} & $17.55 \pm 3.57$ & $82.45 \pm 3.57$ & 1 & $97.81 \pm 0.74$ & $50.36 \pm 14.45$ & $0.83 \pm 0.04$ \\
\hline & & & 2 & $2.02 \pm 0.60$ & $30.98 \pm 2.85$ & \\
\hline & & & 3 & $0.11 \pm 0.10$ & $7.90 \pm 5.61$ & \\
\hline & & & 4 & $0.06 \pm 0.04$ & $10.76 \pm 5.98$ & \\
\hline \multirow[t]{4}{*}{$\mathrm{Cb}+$ acTGase $(0.5 \mathrm{U})$} & $11.28 \pm 1.28$ & $88.72 \pm 1.28$ & 1 & $97.57 \pm 0.52$ & $65.81 \pm 2.65$ & $0.96 \pm 0.03$ \\
\hline & & & 2 & $2.43 \pm 0.52$ & $34.19 \pm 2.65$ & \\
\hline & & & 3 & 0.00 & 0.00 & \\
\hline & & & 4 & 0.00 & 0.00 & \\
\hline \multirow{4}{*}{$\mathrm{Cb}+$ acTGase $(1 \mathrm{U})$} & $12.39 \pm 3.07$ & $81.74 \pm 0.50$ & 1 & $98.31 \pm 0.07$ & $55.73 \pm 1.97$ & $1.26 \pm 0.06$ \\
\hline & & & 2 & $1.61 \pm 0.08$ & $28.81 \pm 1.17$ & \\
\hline & & & 3 & $0.04 \pm 0.06$ & $6.62 \pm 9.37$ & \\
\hline & & & 4 & $0.03 \pm 0.05$ & $8.84 \pm 12.50$ & \\
\hline \multirow[t]{4}{*}{$\mathrm{Cb}+$ acTGase (2 $\mathrm{U})$} & $18.26 \pm 0.50$ & $81.74 \pm 0.50$ & 1 & $97.77 \pm 0.59$ & $52.94 \pm 4.90$ & $1.17 \pm 0.02$ \\
\hline & & & 2 & $2.11 \pm 0.55$ & $35.24 \pm 2.10$ & \\
\hline & & & 3 & $0.06 \pm 0.08$ & $4.35 \pm 6.15$ & \\
\hline & & & 4 & $0.04 \pm 0$ & $7.47 \pm 3.35$ & \\
\hline \multirow[t]{4}{*}{$\mathrm{Sb}$} & $17.18 \pm 1.08$ & $82.82 \pm 1.08$ & 1 & $97.08 \pm 0.68$ & $57.40 \pm 11.72$ & $1.00 \pm 0.03$ \\
\hline & & & 2 & $2.92 \pm 0.68$ & $42.60 \pm 11.72$ & \\
\hline & & & 3 & 0.00 & 0.00 & \\
\hline & & & 4 & 0.00 & 0.00 & \\
\hline \multirow[t]{4}{*}{$\mathrm{Sb}+$ acTGase $(0.5 \mathrm{U})$} & $26.79 \pm 1.06$ & $73.21 \pm 1.06$ & 1 & $94.66 \pm 0.10$ & $24.35 \pm 4.78$ & $1.02 \pm 0.01$ \\
\hline & & & 2 & $4.70 \pm 0.09$ & $40.04 \pm 7.31$ & \\
\hline & & & 3 & $0.41 \pm 0.01$ & $18.98 \pm 4.69$ & \\
\hline & & & 4 & $0.21 \pm 0.21$ & $16.63 \pm 16.78$ & \\
\hline \multirow[t]{4}{*}{$\mathrm{Sb}+$ acTGase (1 U) } & $18.27 \pm 1.16$ & $81.73 \pm 1.16$ & 1 & $93.57 \pm 0.55$ & $37.33 \pm 4.83$ & $0.96 \pm 0.00$ \\
\hline & & & 2 & $6.37 \pm 0.47$ & $59.37 \pm 0.15$ & \\
\hline & & & 3 & 0.06 & $3.31 \pm 4.68$ & \\
\hline & & & 4 & 0.00 & 0.00 & \\
\hline \multirow[t]{4}{*}{$\mathrm{Sb}+$ acTGase (2 U) } & $18.11 \pm 1.60$ & $81.89 \pm 1.60$ & 1 & $94.56 \pm 0.41$ & $42.33 \pm 1.21$ & $0.97 \pm 0.01$ \\
\hline & & & 2 & $5.42 \pm 0.37$ & $56.41 \pm 0.51$ & \\
\hline & & & 3 & $0.03 \pm 0.04$ & $1.26 \pm 1.78$ & \\
\hline & & & 4 & 0.00 & 0.00 & \\
\hline
\end{tabular}

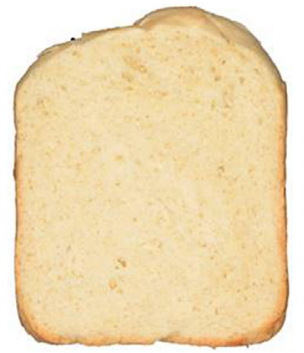

$\mathrm{Cb}$

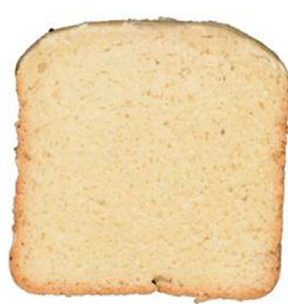

$\mathrm{Sb}$

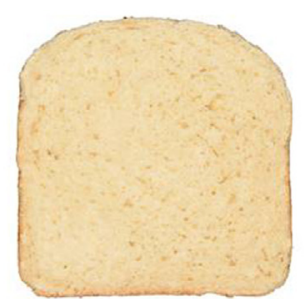

$\mathrm{Cb}+\mathrm{acTGase}(0.5 \mathrm{U})$

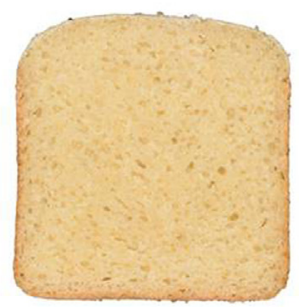

$\mathrm{Sb}+\mathrm{acTGas}(0.5 \mathrm{U})$

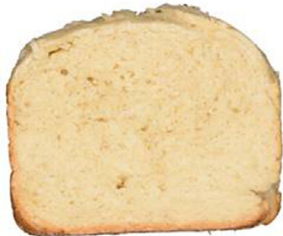

Cb+acTGase (1 U)

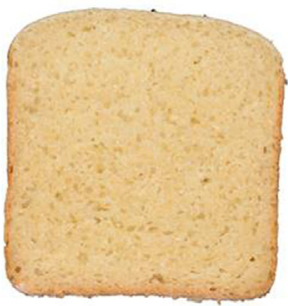

$\mathrm{Sb}+\mathrm{acTGase}(1 \mathrm{U})$

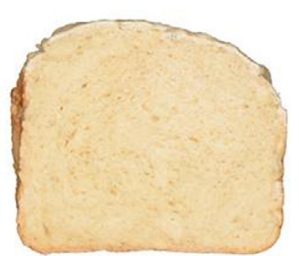

$\mathrm{Cb}+\mathrm{acTGase}(2 \mathrm{U})$

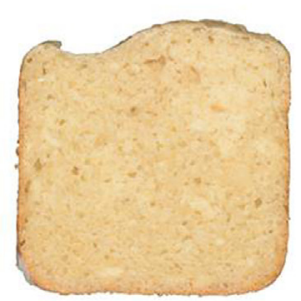

$\mathrm{Sb}+\mathrm{acTGase}(2 \mathrm{U})$

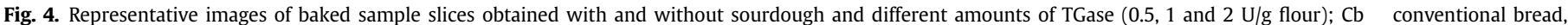
$\mathrm{Cb}+$ acTGase conventional bread supplied with acTGase, $\mathrm{Sb}$ sourdough bread, $\mathrm{Sb}+$ TGase sourdough bread supplied with acTGase.

peptides from gluten obtained through the activity of TGase showed antimicrobial activity (Gottardi et al., 2014). The release of such peptides can play a role in the modulation of bread microbiota during the storage and consequently on final product shelf life. Caballero et al. (2007) showed an increase of staling when this enzyme is used in gluten based bread. However, Collar and Bollaìn 

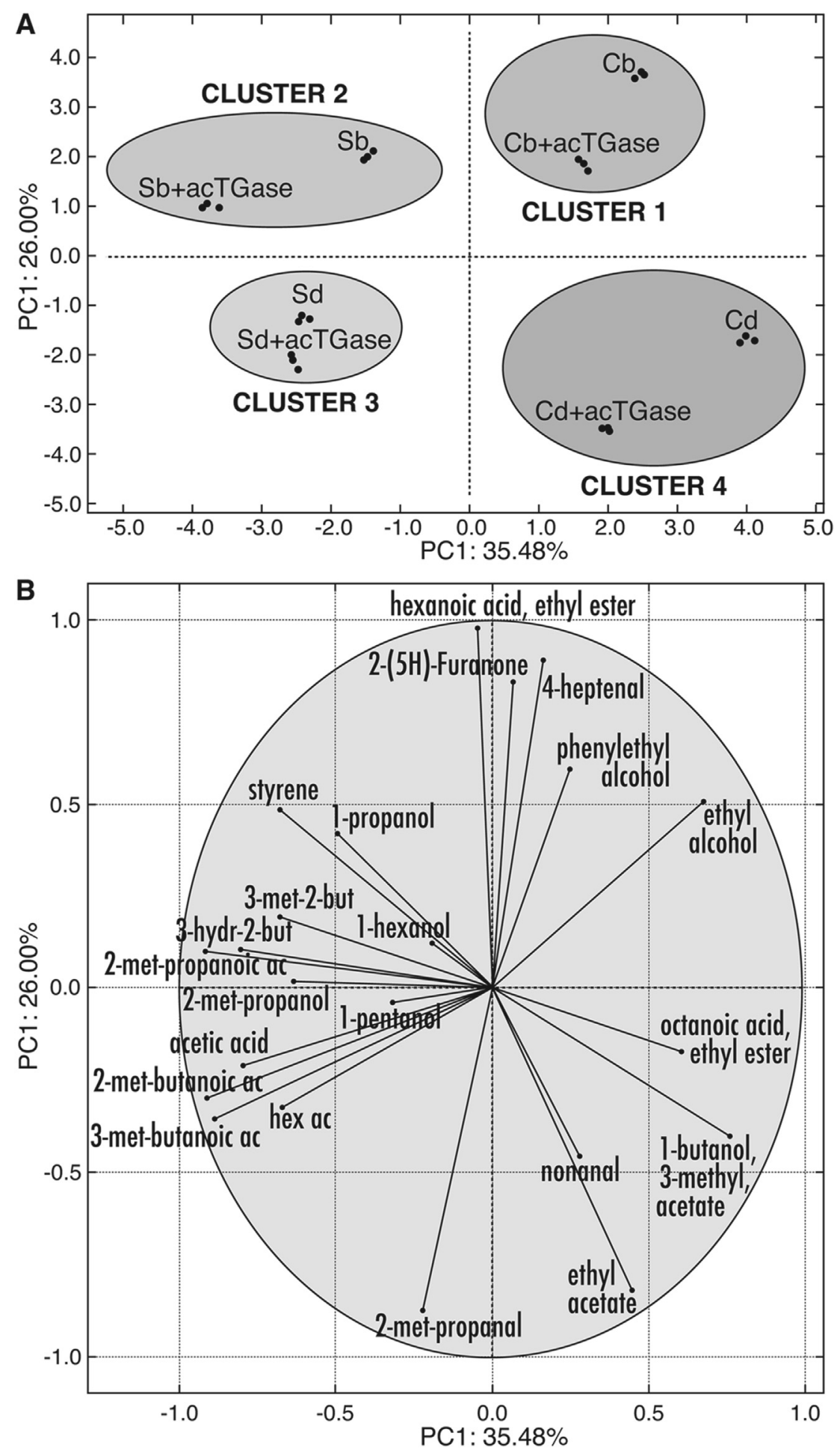

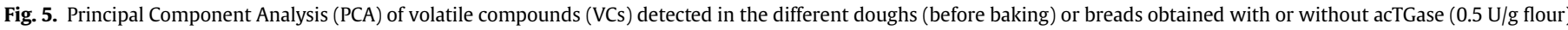

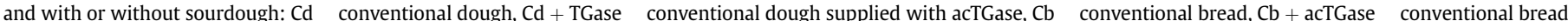

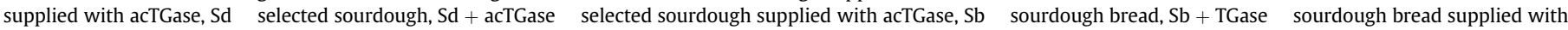

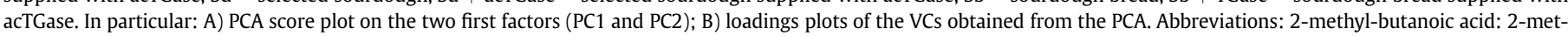

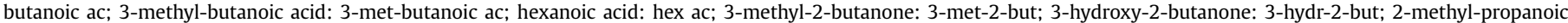
acid: 2-met-propanoic ac; 2-methyl-propanal: 2-met-propanal.

(2005) reported that the combined use of TGase and $\alpha$ amylase reduced crumb staling kinetics and sensory deterioration (Collar \& Bollaìn, 2005). In our experimental conditions, the use of sourdough assured the presence of $\alpha$ amylase released by microbial activity (Sieuwerts, de Bok, Hugenholtz, \& van Hylckama Vlieg, 2008), and therefore mitigated the bread staling properties of TGase. 


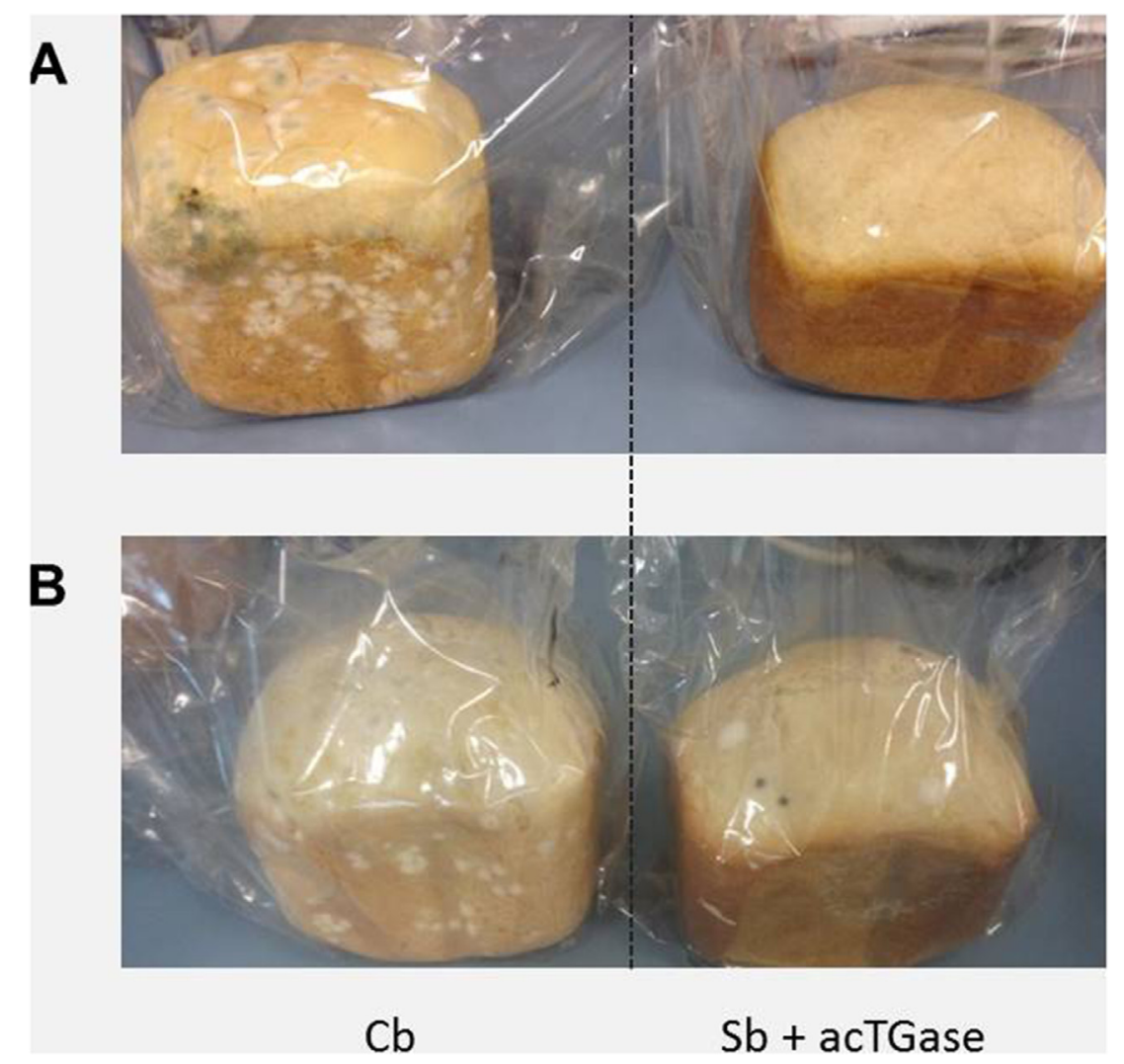

Fig. 6. Shelf-life of baked products obtained using sourdough and $0.5 \mathrm{U} / \mathrm{g}$ flour of acTGase ( $\mathrm{Sb}+\mathrm{acTGase})$, compared to conventional bread (Cb); A) breads after 1 week of storage at $\mathrm{RT}\left(24 \pm 2^{\circ} \mathrm{C}\right)$; B $)$ breads after 2 weeks of storage at RT.

\section{Conclusions}

In this work, the synergistic beneficial effects on bread characteristics of microbial acTGase and a consortium of $L$. sanfranciscensis and $C$. milleri in bread making are described. The excessive hard ness and chewiness of $\mathrm{Cb}$ caused by increasing concentrations of acTGase were counteracted by the addition of a proper amount of sourdough. On the other hand, the degradative action of sourdough on protein substrates, which reduces the viscoelastic properties of bread, was compensated by the protein aggregating effect of TGase. In summary, the use of sourdough combined with acTGase showed positive effects on bread rheological features, shelf life, and aroma profile.

\section{Funding}

This work was supported by the project MISE-Industria 2015, ATENA (MI01_00093) focused on the development of a meal kit representing the Mediterranean diet.

\section{Acknowledgements}

We acknowledge Ajinomoto Foods Europe SAS for the supply of the Activa transglutaminase batch used in this study. We are grateful to S. Biondi for the revision of the English language.

\section{References}

Aponte, M., Boscaino, F., Sorrentino, A., Coppola, R., Masi, P., \& Romano, A. (2014). Effects of fermentation and rye flour on microstructure and volatile compounds of chestnut flour based sourdoughs. LWT - Food Science and Technology, 58, 387 395.

Arendt, E. K., Ryan, L. A., \& Dal Bello, F. (2007). Impact of sourdough on the texture of bread. Food Microbiology, 24(2), 167174.

Basman, A., Koksel, H., \& Ng, P. K. W. (2002). Effects of increasing levels of transglutaminase on the rheological properties and bread quality characteristics of two wheat flours. European Food Research and Technology, 215, 419 424. Caballero, P. A., Gómez, M., \& Rosell, C. M. (2007). Improvement of dough rheology,

bread quality and bread shelf-life by enzymes combination. Journal of Food Engineering, 81(1), 4253.

Chavan, R. S., \& Chavan, S. R. (2011). Sourdough technology-a traditional way for wholesome foods: A review. Comprehensive Reviews in Food Science and Food Safety, 10(3), 169182

Clarke, C. I., Schober, T. J., \& Arendt, E. K. (2002). Effect of single strain and traditional mixed strain starter cultures on rheological properties of wheat dough and on bread quality. Cereal Chemistry Journal, 79(5), 640647.

Collar, C., \& Angioloni, A. (2014). Pseudocereals and teff in complex breadmaking matrices: Impacton lipid dynamics. Journal of Cereal Science, 59(2), 145 154. Collar C., \& Bollaìn, C. (2005). Impact of microbial transglutaminase on the staling behavior of enzyme-supplemented pan breads. European Food Research Technology, 221, 298304

Corsetti, A., Gobetti, M., De Marco, B., Balestrieri, F., Paoletti, F., Russi, L., et al. (2000). Combined effect of sourdough lactic acid bacteria and additives on bread firmness and staling. Journal of Agricultural and Food Chemistry, 48(7), 30443051.

Crowley, P., Schober, T. J., Clarke, I. C., \& Arendt, E. K. (2002). The effect of storage time on textural and crumb grain characteristics of sourdough wheat bread European Food Research and Technology, 214, 489496.

Damiani, P., Gobbetti, M., Cossignani, L., Corsetti, A., Simonetti, M. S., \& Rossi, J. (1996). The sourdough microflora. Characterization of hetero- and homofermentative lactic acid bacteria, yeasts and their interactions on the basis of the volatile compounds produced. Food Science and Technology, 29, 6370.

De Vuyst, L., \& Neysen, P. (2005). The sourdough microflora: Biodiversity and metabolic interactions. Trends in Food Science \& Technology, 16, 4356

De Vuyst, L., Van Kerrebroeck, S., Harth, H., Huys, G., Daniel, H. M., \& Weckx, S (2014). Microbial ecology of sourdough fermentations: Diverse or uniform? Food Microbiology, 37, 1129.

Della Mea, M., Caparros-Ruiz, D., \& Rigau, J. (2004). AtPng1p: The first plant transglutaminase. Plant physiology, 135, 20462054.

Di Cagno, R., De Angelis, M., Alfonsi, G., De Vincenzi, M., Silano, M., Vincentini, O., et al. (2005). Pasta made from durum wheat semolina fermented with selected lactobacilli as a tool for a potential decrease of the gluten intolerance. Journal of Agricultural and Food Chemistry, 53, 43934402.

Erasmus, D. J., Van Der Merwe, G. K., \& Van Vuuren, H. J. J. (2003). Genome-wide 
expression analyses: Metabolic adaptation of Saccharomyces cerevisiae to high sugar stress. FEMS Yeast Research, 3(4), 375399.

Gambaro, A., Varela, P., Gimenez, A., Aldrovandi, A., Fiszman, S. M., \& Hough, G. (2002). Textural quality of white pan bread by sensory and instrumental measurements. Journal of Texture Studies, 33(5), 401413.

Ganzle, M. G., Ehmann, M., \& Hammes, W. P. (1998). Modeling of growth of Lactobacillus sanfranciscensis and Candida milleri in response to process parameters of sourdough fermentation. Applied and environmental microbiology, 64(7), 26162623.

Ganzle, M. G., Vermeulen, N., \& Vogel, R. F. (2007). Carbohydrate, peptide and lipid metabolism of lactic acid bacteria in sourdough. Food Microbiology, 24(2),

128138.

Gerrard, J. A., Fayle, S. E., Wilson, A. J., Newberry, M. P., Ross, M., \& Kavale, S. (1998). Dough properties and crumb strength of white pan bread as affected by mi-crobial transglutaminase. Journal of Food Science, 63(3), 472475.

Gerrard, J. A., Newberry, M. P., Ross, M., Wilson, A. J., Fayle, S. E., \& Kavale, S. (2000). Pastry lift and croissant volume as affected by microbial transglutaminase.

Journal of Food Science, 65(2), 312314.

Gobbetti, M. (1998). The sourdough microflora: Interactions of lactic acid bacteria and yeasts. Trends in Food Science \& Technology, 9(7), 267274

Gobbetti, M., Smacchi, E., \& Corsetti, A. (1996). The proteolytic system of Lactobacillus sanfrancisco CB1: Purification and characterization of a proteinase, a dipeptidase, and an aminopeptidase. Applied and Environmental Microbiology, 62(9), 32203226.

Gottardi, D., Khoon Hong, P., Ndagijimana, M., \& Betti, M. (2014). Conjugation of gluten hydrolysates with glucosamine at mild temperatures enhances antioxidant and antimicrobial properties. LWT - Food Science and Technology, 57, 181187.

Guerzoni, M. E., Vernocchi, P., Ndagijimana, M., Gianotti, A., \& Lanciotti, R. (2007). Generation of aroma compounds in sourdough: Effects of stress exposure and lactobacilli-yeasts interactions. Food Microbiology, 24(2), 139148.

Hansen, A., \& Schieberle, P. (2005). Generation of aroma compounds during sourdough fermentation: Applied and fundamental aspects. Trends in Food Science \& Technology, 16, 8594.

Kirchhoff, E., \& Schieberle, P. (2001). Determination of key aroma compounds in the crumb of a tree-stage sourdough rye bread by stable isotope dilution assays and sensory studies. Journal of Agricultural and Food Chemistry, 49(9), 43044311.

Koksel, H., Sivri, D., Ng, P. K. W., \& Steffe, J. F. (2001). Effects of Transglutaminase enzyme on fundamental rheological properties of sound and bug-damaged wheat flour doughs. Cereal Chemistry Journal, 78, 2630.

Larre, C., Denery-Papini, S., Popineau, Y., Deshayes, G., Desserme, C., \& Lefebvre, J. (2000). Biochemical analysis and rheological properties of gluten modified by transglutaminase. Cereal Chemistry Journal, 77, 121127.

Lilley, G. R., Skill, J., Griffin, M., \& Bonner, P. L. (1998). Detection of Ca2+-dependent transglutaminase activity in root and leaf tissue of monocotyledonous and dicotyledonous plants. Plant physiology, 117(3), 11151123.

Loponen, J., Mikola, M., Katina, K., Sontag-Strohm, T., \& Salovaara, H. (2004). Degradation of HMW glutenins during wheat sourdough fermentations. Cereal Chemistry Journal, 81, 8793.

Marco, C., Perez, G., Ribotta, P., \& Rosselli, C. M. (2007). Effect of microbial transglutaminase on the protein fractions of rice, pea and their blends. Journal of the Science of Food and Agriculture, 87, 25762582.
Minervini, F., De Angelis, M., Di Cagno, R., \& Gobbetti, M. (2014). Ecological parameters influencing microbial diversity and stability of traditional sourdough. International Journal of Food Microbiology, 3(171), 136146.

Montanari, C., Bargossi, E., Gardini, A., Lanciotti, R., Magnani, R., Gardini, F., et al (2016). Correlation between volatile profiles of Italian fermented sausages and their size and starter culture. Food Chemistry, 192, 736744

Montanari, C., Bargossi, E., Lanciotti, R., Chinnici, F., Gardini, F., \& Tabanelli, G. (2014) Effects of two different sourdoughs on the characteristics of Pandoro, a typical Italian sweet leavened baked good. LWT - Food Science and Technology, 59(1), 289299.

Nonaka, M., Tanaka, H., Okiyama, A., Motoki, M., Ando, H., Umeda, K., et al. (1989). Polymerization of several proteins by $\mathrm{Ca}^{2+}$-independent transglutaminase derived from microorganisms. Agricultural and Biological Chemistry, 53, 26192623.

Patrignani, F., Montanari, C., Serrazanetti, D. I., Braschi, G., Vernocchi, P., Tabanelli, G..... Lanciotti, R. (2016). Characterisation of yeast microbiota, wines. Annals of Microbiology. http://dx.doi.org/10.1007/s13213-016-1241-3.

Poutanen, K., Flander, L., \& Katina, K. (2009). Sourdough and cereal fermentation in a nutritional perspective. Food Microbiology, 26(7), 693699.

Renzetti, S., Behr, J., Vogel, R. F., \& Arendt, E. K. (2008). Transglutaminase polymerisation of buckwheat (Fagopyrum esculentum Moench) proteins. Journal of Cell Science, 48(3), 747754

Rizzello, C. G., De Angelis, M., Di Cagno, R., Camarca, A., Silano, M., Losito, I., .. Gobbetti, M. (2007.). Highly efficient gluten degradation by lactobacilli and fungal proteases during food processing: New perspectives for celiac
disease. Applied and Environmental Microbiology, 73(14), 44994507.

Scarnato, L., Serrazanetti, D. I., Aloisi, I., Montanari, C., Lanciotti, R., \& Del Duca, S. (2016). Combination of transglutaminase and sourdough on gluten-free flours to improve dough structure. Amino Acids, 48(10), 24532465.

Serrazanetti, D. I., Guerzoni, M. E., Corsetti, A., \& Vogel, R. (2009). Metabolic impact and potential exploitation of the stress reactions in lactobacilli. Food Microbiol., 26(7), 700711.

Sieuwerts, S., de Bok, F. A. M., Hugenholtz, J., \& van Hylckama Vlieg, J. E. T. (2008) Uraveling microbial interactions in food fermentations: From classical to ge-

nomics approaches. Applied and Environmental Microbiology, 46, 4997 5007. Smith, P. K., Krohn, R. I., Hermanson, G. T., Mallia, A. K., Gartner, F. H., Provenzano, M. D., ... Klenk, D. C. (1985). Measurement of protein using bicin-choninic acid. Analytical Biochemistry, 150(1), 7685.

Steffolani, M. E., Ribotta, P. D., Perez, G. T., \& Leon, A. E. (2010). Effect of glucose oxidase, transglutaminase, and pentosanase on wheat proteins: Relationship with dough properties and bread-making quality. Journal of Cell Science, 51,366373 .

Stollman, U., \& Lundgren, B. (1987). Texture changes in white bread: Effects of processing and storage. Cereal Chemistry Journal, 64(4), 230236.

Thanh, V. H., Okubo, K., \& Shibasaki, K. (1975). Isolation and characterization of the multiple 7S globulins of soybean proteins. Plant Physiology, 56, 19 22. Vernocchi, P., Ndagijimana, M., Serrazanetti, D. I., Gianotti, A., Vallicelli, M., \& Guerzoni, M. E. (2008). Influence of starch addition and dough microstructure on fermentation aroma production by yeasts and lactobacilli. Food Chemistry, 108,12171225 . 